\title{
Exposição de crianças à mídia eletrônica e processos miméticos
}

CHILDREN EXPOSURE TO ELECTRONIC MEDIA, AND MIMETIC PROCESSES

\section{Malena Segura Contrera}

Doutora em Comunicação e Semiótica pela Pontifícia Universidade Católica de São Paulo

(PUC-SP). Docente do Programa de Pós-graduação em Comunicação da Universidade

Paulista (Unip). Líder do GP em Mídia e Estudos do Imaginário. Pesquisadora PQ do CNPq.

E-mail: malenacontrera@uol.com.br

\section{Sueli Ferreira Schiavo}

Psicóloga, mestre e doutoranda em Comunicação pela Unip, membro do GP em Mídia e Estudos do Imaginário.

E-mail: suelischiavo@gmail.com

Recebido em 25 de janeiro de 2017. Aprovado em 26 de maio de 2017.

\section{Resumo}

Este texto reflete sobre o fenômeno humano da mimese. Observa-se que o incentivo ao uso de aparatos tecnológicos por meio de estratégias estéticas e mercadológicas caminhou com a produção de conteúdos específicos produzidos que induzem ao consumo de bens e serviços especialmente voltados para o público infantil. Concluise que há questões a serem consideradas pelos agentes sociais acerca do uso desmedido e não monitorado dos aparatos eletrônicos pelas crianças. A fundamentação teórica considera a contribuição de Christoph Wulf, Vilém Flusser e Norval Baitello Jr., entre outros.

Palavras-chave: Criança. Mídia eletrônica. Mimese.

\section{Abstract}

This text reflects on the human phenomenon of mimesis. We notice that encouraging the use of technological devices through aesthetic and marketing strategies walked along with the production of specific content, leading to the consumption of goods and services especially geared to children. We conclude that there are issues to consider by social agents on the excessive and unmonitored use of electronic devices by children. Our theoretical foundation considers the contribution of Christoph Wulf, Flusser and Norval Baitello Jr., among others.

Keywords: Child. Electronic media. Mimesis. 


\section{Introdução}

$\mathrm{O}$ advento da eletricidade mudou o mundo de muitas e diferentes formas, como sabemos, mas foi a partir da segunda metade do século 20 que as tecnologias eletrônicas de comunicação se desenvolvem e tornam seus produtos comercializáveis em grande escala, gerando um impacto na formação de grandes públicos e causando um maior impacto na sociabilidade e na ecologia das imagens e do imaginário. Baitello Junior (2010, p. 71) entende que "os processos exploratórios de instalação das redes de eletricidade foram de fundamental importância como expansão de um modelo civilizatório e de um modelo econômico na produção crescente de bens (portanto também expansivo)". A primeira década do século 21 presencia o boom dos jogos eletrônicos voltados às crianças ${ }^{1}$, e o uso constante dos aparatos tecnológicos de comunicação por parte destas passa a ser considerado um avanço social. É isso que é problematizado neste texto, considerando-se que há riscos associados a esse uso - e aos seus excessos - que não são debatidos pela sociedade e não vêm sendo suficientemente investigados pelas pesquisas que se dedicam a essa relação entre infância e uso de eletrônicos, com algumas exceções².

Valendo-se de uma revisão bibliográfica, o presente artigo investiga as implicações e os resultados trazidos pelas pesquisas empíricas nas quais essa discussão se

1 Conforme o Estatuto da Criança e do Adolescente, “Art. $2^{\circ}$ Considera-se criança, para os efeitos desta Lei, a pessoa até doze anos de idade incompletos, e adolescente aquela entre doze e dezoito anos de idade. Parágrafo único. Nos casos expressos em lei, aplica-se excepcionalmente este Estatuto às pessoas entre dezoito e vinte e um anos de idade. Art. $3^{\circ} \mathrm{A}$ criança e o adolescente gozam de todos os direitos fundamentais inerentes à pessoa humana, sem prejuízo da proteção integral de que trata esta Lei, assegurando-se-lhes, por lei ou por outros meios, todas as oportunidades e facilidades, a fim de lhes facultar o desenvolvimento físico, mental, moral, espiritual e social, em condições de liberdade e de dignidade. Parágrafo único. Os direitos enunciados nesta Lei aplicam-se a todas as crianças e adolescentes, sem discriminação de nascimento, situação familiar, idade, sexo, raça, etnia ou cor, religião ou crença, deficiência, condição pessoal de desenvolvimento e aprendizagem, condição econômica, ambiente social, região e local de moradia ou outra condição que diferencie as pessoas, as famílias ou a comunidade em que vivem. Art. $4^{\circ}$ É dever da família, da comunidade, da sociedade em geral e do poder público assegurar, com absoluta prioridade, a efetivação dos direitos referentes à vida, à saúde, à alimentação, à educação, ao esporte, ao lazer, à profissionalização, à cultura, à dignidade, ao respeito, à liberdade e à convivência familiar e comunitária. Parágrafo único. A garantia de prioridade compreende: a) primazia de receber proteção e socorro em quaisquer circunstâncias; b) precedência de atendimento nos serviços públicos ou de relevância pública; c) preferência na formulação e na execução das políticas sociais públicas; d) destinação privilegiada de recursos públicos nas áreas relacionadas com a proteção à infância $\mathrm{e}$ à juventude. Art. $5^{\circ}$ Nenhuma criança ou adolescente será objeto de qualquer forma de negligência, discriminação, exploração, violência, crueldade e opressão, punido na forma da lei qualquer atentado, por ação ou omissão, aos seus direitos fundamentais. Art. $6^{\circ} \mathrm{Na}$ interpretação desta Lei levar-se-ão em conta os fins sociais a que ela se dirige, as exigências do bem comum, os direitos e deveres individuais e coletivos, e a condição peculiar da criança e do adolescente como pessoas em desenvolvimento". Disponível em: <goo.gl/ CWqd98>. Acesso em 23 out. 2017.

$2 \mathrm{Na}$ área de Comunicação, uma bela exceção tem sido os trabalhos desenvolvidos pelo Grupo de Pesquisa da Relação Infância, Adolescência e Mídia, da Universidade Federal do Ceará, coordenado pela Profa. Dra. Inês Vitorino. 
baseia ${ }^{3}$, especificamente no que tange às consequências da crescente exposição da criança à mídia eletrônica, em relação ao decrescente hábito de explorar o meio ambiente presencialmente. Ao falarmos de imagens técnicas nos referimos à contribuição de Vilém Flusser $(1985,1989)$ e de Baitello Junior (2010), conforme veremos mais adiante.

A questão requer que se possa compreender as diferenças existentes entre a imagem técnica e a imagem simbólica, esta primeira limitante da capacidade de imaginar. As imagens simbólicas são portadoras de uma abertura para o imaginário cultural, cumulativo, portador da herança cultural e antropológica da humanidade. Imagens técnicas são sintéticas, produzidas por e portadoras de recursos tecnológicos específicos. Acerca desta distinção temos que: "Não por acaso as imagens mediáticas, em sua quase totalidade imagens técnicas, sucedem-se vertiginosamente, sem que tenhamos a menor chance de dedicar a alguma delas o tempo lento da imaginação" (CONTRERA, 2015, p. 9). Já acerca das imagens simbólicas sabemos: "A imagem simbólica, pelo contrário, é portadora de uma enorme concentração de energia, ela é um vórtex que irradia energia psíquica, partindo da psique coletiva, enredando-nos numa teia invisível ancestral, arquetípica" (Ibid., 2015, p. 9).

As imagens técnicas presentes na mídia eletrônica passam por todo um processo de edição feito por agentes específicos da comunicação, alinhados a uma visão de mundo que vê principalmente na imagem uma mercadoria rentável. A edição das imagens, como toda edição, tem a função de apresentar um recorte que se propõe a direcionar a atenção para alguns elementos que se apresentam como "o que vale a pena mostrar", destruindo os contextos originais de algumas imagens e reapresentando-as em novos contextos, criados especificamente para gerar o máximo de impacto sensorial, rápida deglutição e pouca ressonância simbólica. A sequência e a velocidade com que se apresentam essas imagens permitem pouco tempo de reflexão sobre elas, e por isso elas não cumprem o papel criativo das imagens, ou seja, penetrar a alma e agitar a imaginação. Segundo Baitello Jr. (2010, p. 69-70), “a imagem visual na comunicação humana contemporânea possui algo de irresistível e algo de misterioso, algo de miragem". Mas a miragem, nesse caso, é sempre fantasmagórica, é a ilusão no deserto dos afetos, o que se torna especialmente

3 Cita em entrevista, William Nozaki, que participou da pesquisa da Fundação Perseu Abramo divulgada em março de 2017: "exemplos muito curiosos na pesquisa, e teve uma mulher que me chamou muito a atenção. Ela trabalha, tinha dificuldade para encontrar alguém que cuidasse da filha e assinou a TV a cabo com uma parte de recursos do Bolsa Família, porque era o único jeito de ela conseguir manter a filha em casa, deixando a TV ligada o dia inteiro no Cartoon Network. Uma forma que ela encontrou para lidar com um problema relacionado à falta de creches. Não dá para classificar isso como consumismo. Na verdade, as pessoas estão tentando buscar alternativas para organizar sua vida e, evidentemente, em uma sociedade de mercado, essas alternativas vão passar pelo trabalho e pelo consumo". Disponível em: <goo.gl/dQKGfi>. Acesso em: 23 out. 2017. 
adequado quando pensamos nas crianças que ficam muitas horas isoladas em seus tablets e smartphones, alienadas do convívio da família que, ou não está presente fisicamente, ou não interage com a criança ${ }^{4}$.

A família, no entanto, não vê nessa hiperexposição aos aparatos mediáticos eletrônicos nenhum mal, já que, como coloca Jorge Miklos (2014), o discurso que insere as tecnologias de comunicação na sociedade as apresentam como um imperativo para a vida contemporânea, favorecedora de sociabilidade e como um imprescindível instrumento para a educação e para o aprendizado em geral. É claro que esse é um discurso ideologicamente comprometido, pois esconde toda a dimensão econômica e ideológica embutida nas tecnologias da comunicação, apresentando-a como o caminho para o progresso.

Não temos muita resistência com imagens, já que estão presentes no fundamento do próprio humano (MORIN, 1988), ou ainda, como apresenta Baitello Junior (2010, p. 70), "seu caráter e seu poder de sedução estão plantados em solo de camadas muito profundas na história da alma humana". Daí o papel da imagem como ordenadora de sentidos, crenças e valores.

\section{Imagens técnicas e violência - novas formas de abuso}

Na produção e disseminação de conteúdos mediáticos, os representantes dos meios de produção e de conglomerados privados de mídia não debatem com a sociedade sobre as cenas de violência, menos ainda sobre o papel dessas imagens na constituição do imaginário da criança. Não se reflete sobre o quanto imagens de violência ${ }^{5}$ potencializam as várias formas de violência, como se fosse tácita a crença na ação asséptica das imagens.

4 Conforme dados apurados, por exemplo: "O tempo médio por dia que crianças e adolescentes passam em frente à televisão tem subido constantemente, em 10 anos (entre 2004 e 2014) foi registrado um aumento de 52 minutos. Os dados fazem parte do Painel Nacional de Televisão, do Ibope Media, que registra a evolução do tempo dedicado à TV (canais abertos e fechados, não inclui os programas assistidos sob demanda) por crianças e adolescentes entre 4 e 17 anos de todas as classes sociais. O tempo foi contabilizado diariamente por meio do people meter em 15 regiões metropolitanas do Brasil”. Disponível em: <goo.gl/b9ga6a >. Acesso em: 23 out. 2017.

5 Esclarecendo "imagens de violência", segundo texto elaborado pelo Centro de Referência em Assistência Social (Creas) de Ipiaú na Bahia, tudo que possa ser demonstrado em imagens, apontando o que consta a seguir, considera-se violência contra crianças e adolescentes: "Violência física: Atos violentos com o uso da força física de forma intencional - não acidental - provocada por pais, responsáveis, familiares ou pessoas próximas. Negligência: Omissão dos pais ou responsáveis quando deixam de prover as necessidades básicas para o desenvolvimento físico, emocional e social da criança e do adolescente. Psicológica: Rejeição, privação, depreciação, discriminação, desrespeito, cobranças exageradas, punições humilhantes, utilização da criança e adolescentes para atender às necessidades dos adultos. Sexual: Toda a ação que envolve ou não o contato físico, não apresentando necessariamente sinal corporal visível. Pode ocorrer a estimulação sexual sob a forma de práticas eróticas e sexuais (violência física, ameaças, indução, voyerismo, exibicionismo, produção de fotos e exploração sexual)". Disponível em: <goo.gl/L4gu4b>. Acesso em: 23 out. 2017. 
O mapa da violência apresenta dados estatísticos ${ }^{6}$ assustadores sobre o que se tem apurado acerca da violência social, suscitando discussões acerca de diferentes fatores que podem estar implicados nesse quadro, no entanto, quase não há discussão sobre as repercussões da violência reproduzida nos conteúdos de televisão, videogames etc. Há muitos programas direcionados às crianças que banalizam a violência, fazem da perversidade uma prática cotidiana, fazem uso excessivo do apelo ao grotesco, sem que haja sequer o debate acerca do que isso possa gerar no imaginário. Aliás, faz parte do projeto econômico de elogio irrestrito aos meios de comunicação eletrônicos subestimar a repercussão imaginária de seus produtos e conteúdos. Segundo Durand (1993), o imaginário, este indesejável, nunca foi convidado de honra nos banquetes do poder, talvez por seu potencial de rebeldia e seu caráter indomável. Para Muniz Sodré (2002), o imaginário pode ser indomável, mas sempre podemos criar uma esfera imaginária que se possa controlar, uma bolha pautada pela repetição e sucessão veloz das imagens técnicas.

Videogames, desenhos, peças publicitárias, entre outros produtos, promovem uma sequência de exploração de imagens técnicas e chegam à criança por meio de aparatos tecnológicos que exploram o sentido da visão e da audição, pondo o corpo em um processo de subordinação por conta da atenção requerida pela recepção das imagens.

$\mathrm{O}$ aperfeiçoamento - tanto estético quanto de disponibilização de funcionalidades - na industrialização dos aparelhos eletrônicos tem promovido um processo de permanente conexão entre sistemas que têm permitido ao cidadão, na qualidade de usuário, dispor de serviços cada vez mais diversificados. O mote constante das peças publicitárias que vendem tecnologia de comunicação é que a tecnologia traz soluções para tarefas cotidianas e ainda te poupa do estresse social. Ações humanizadoras e de valorização comunitária passam a fazer parte da agenda da divulgação de conteúdos da mídia eletrônica como estratégias dissimuladas de marketing pessoal ou institucional. Tablets e celulares utilizam diferentes recursos para seduzir, constituindo objeto de desejo de muitos consumidores, no entanto, poucas vezes esses consumidores podem opinar sobre os conteúdos que recebem. Fica difícil para a criança resistir às imagens técnicas que abrigam em si mesmas a violência da estereotipia e a banalização das ações de violência especificamente, além do arrebatamento frente aos apelos da luz e do movimento destas.

Um exemplo atual sobre o que pode ser observado no avanço da produção e distribuição desses aparelhos no Brasil diz respeito ao número de celulares, que é maior do

6 "Mapa da Violência 2013 - Homicídios e Juventude no Brasil, do professor Julio Jacobo Waiselfisz, que compara os índices brasileiros aos resultantes dos conflitos armados. [...] os 206.005 homicídios ocorridos no Brasil, no período de 2008 a 2011, são semelhantes ao total de mortes diretas ocorridas nos 62 conflitos armados pelo mundo nesse espaço de tempo, que é de 208.349". 
que o número de habitantes ${ }^{7}$. A sofisticação dos aparelhos - na apresentação, na convergência de diferentes recursos, na qualidade de sinais de som e imagem, nas conexões à internet, entre outros - tornam a posse de um modelo mais atualizado um instrumento de distinção social, especialmente pela forma como isso é explorado pela publicidade. Em vários casos, ostentar um modelo recente pode ser mais importante do que a efetiva necessidade de usar os recursos disponibilizados pelo aparelho, especialmente quando se pensa em crianças que reivindicam o último modelo para uso quase exclusivo de canais de games e música. E não raro, em grupos privilegiados economicamente, não carregar um desses aparelhos de última geração representa a exclusão social tácita da criança no grupo e nas brincadeiras com os colegas. Pais mais esclarecidos relatam frequentemente o conflito entre deixar seu filho horas a fio conectado, por um lado, ou excluí-lo da "atividade social" do grupo de amigos, por outro; o acompanhamento do responsável por todo o tempo, requerido para o uso consciente desse processo, a supervisão necessária e o constante embate frente à vontade viciada das crianças por conexão constante tornam o exercício responsável da paternidade uma tarefa descomunalmente estressante.

\section{A força da mimese na infância}

Segundo René Girard (2008, p. 4), "homem é o animal mais mimético de todos [...] A imitação deve conceber-se não apenas ao nível das maneiras de falar e de se comportar, mas também ao nível do desejo. Os homens imitam os desejos uns dos outros". Uma das questões que aqui se destaca é que esse desejar nem sempre é consciente, o que constitui um desafio humano ainda maior. Como a capacidade de imaginar vai sendo reduzida e a imagem técnica fetichizada, a questão do desejo passa a adquirir um caráter de imponderabilidade, potencializando sua vocação para a inconsciência.

Christoph Wulf (2013, p. 78) explica que "a mimesis é sempre ocasionada pela rede de relações entre pessoas [...] Muitos processos miméticos são indissociáveis dos processos de cobiçar e desejar sentir e de experimentar". Isso ajuda a entender porque a pessoa precisa ostentar o aparelho como forma de pertencimento da sua rede de relações. Sobre mimese, Wulf (Ibid., p. 77) ainda reforça que "pode-se afirmar que agir e aprender mimeticamente não significa somente 'imitar', 'exprimir', 'antecipar mimeticamente'. Conceitos afins ou vizinhos ao de mimesis são 'mímica', representação, imitação, reprodução, simulação e autopoiesis". Esses conceitos estão relacionados com o conjunto de

7 "O Brasil encerrou 2014 com 280,73 milhões de linhas ativas de telefonia móvel, alta de 3,5\% sobre dezembro de 2013, informou nesta sexta-feira (29) a Agência Nacional de Telecomunicações (Anatel)". Disponível em: <goo.gl/QzMJiK>. Acesso em: 23 out. 2017. 
complexidades do ser humano, especialmente se considerarmos que autopoiesis implica no modo como conhecemos o mundo e nos reinventamos a partir desse conhecimento.

Segundo Humberto Maturana e Francisco Varela (1995, p. 66),

ao examinarmos mais de perto como chegamos a conhecer esse mundo, sempre descobriremos que não podemos separar nossa história de ações - biológicas e sociais - de como ele nos parece ser. É algo tão óbvio e próximo de nós que fica muito difícil percebê-lo.

Nesse sentido, as representações veiculadas pela mídia eletrônica por meio das imagens técnicas oferecem às crianças um modelo claro não do que o mundo é, mas de como ele "parece ser". Se para o adulto a distinção entre o que as coisas parecem ser por meio da experiência e o que elas parecem ser por meio de simulações é mais possível de ser realizada, para a criança essa distinção não é tão simples, especialmente no contexto de uma crescente retirada de situações de experiência concreta de sua rotina, em cidades sem praças e sem espaços concretos de sociabilidade que não sejam shopping centers. Como resultado, uma geração de pessoas que não se interessam absolutamente pelo concreto está sendo criada, e certamente isso é bastante conveniente para a exploração econômica da biosfera, para o consentimento do trabalho escravo, para a implantação das mentalidades fundamentalistas, literalizantes em sua essênciå

\section{A banalização da violência - a banalização do mal}

As muitas imagens técnicas pelas quais o mundo é representado pela criança através dos meios eletrônicos incentivam um modelo de entendimento que banaliza a violência. Segundo Contrera (2015, p. 3), as pessoas parecem ignorar a "importância da relação entre a imagem e o tipo de consciência que a percebe e que a imagina". Para Contrera, a condição prévia do entendimento que uma pessoa terá de um conteúdo da mídia, além da sua imersão cultural, depende de um repertório pessoal, que precisa ser rico e reflexivo. Tanto o meio quanto as vivências e capacidades individuais interferem na construção do sentido de algo que é recebido, caracterizando processos internos em sua grande maioria inconscientes e que dizem respeito à rede de relações, às questões de natureza psicológica, social, cultural, de modo que não se pode garantir que um indivíduo tenha condições necessárias de filtrar e processar os conteúdos recebidos, relativizando seu impacto na formação de comportamentos aprendidos. Isso se

8 Acerca desse tema, remetemos ao artigo “Jornalismo e mídia - paranoia e crise das competências simbólicas”, reflexão de 2002, inspirada pelo livro Paranoia, de James Hillman. 
torna especialmente relevante como no caso dos conteúdos de violência apreendidos por crianças. Afinal, "há uma sinergia entre imagem e consciência imaginante que não pode ser ignorada" (CONTRERA, 2015, p. 3).

A mídia eletrônica que opera por meio das imagens técnicas apresenta esse mundo por uma janela, que poderia ser uma oportunidade de acesso, mas que abriga também um risco. Considera Vilém Flusser (1985, p. 7):

Imagens têm o propósito de representar o mundo. Mas, ao fazê-lo, entrepõem-se entre mundo e homem. Seu propósito é serem mapas do mundo, mas passam a ser biombos. O homem, ao invés de se servir das imagens em função do mundo, passa a viver em função de imagens.

Quais as implicações que poderiam advir do fato de que a criança tem hoje entre ela e o mundo uma infinidade de imagens biombo? As imagens técnicas cumprem um papel de reduzir os sonhos, a magia e a imaginação, pois passa a ser apenas uma representação infinitamente mais pobre sensorial e cognitivamente do que as imagens formadas a partir das experiências corporais concretas. Se considerarmos que, no Brasil, um levantamento feito pela revista Crescer com 1.045 mães e pais de crianças de 0 a 8 anos mostrou que $40 \%$ das crianças de 5 a 8 anos já têm seu próprio tablet e que $76 \%$ das crianças acessam o computador diariamente, sendo ainda que 59\% das crianças de até dois anos passam de 30 minutos a 2 horas usando o smartphone todos os dias (REIS, 2013), podemos avaliar a seriedade da questão.

Para muitas crianças há a possibilidade das imagens técnicas se constituírem como a principal experiência da realidade, como podemos confirmar pelos índices de exposição acima citados, porque é tudo com o que elas mais convivem.

O comportamento mimético cria o vínculo de pertencimento com o grupo social no qual estamos inseridos, e nesse processo as imagens são carregadas da memória cumulativa de uma cultura. Entretanto, a mimese é explorada pelos responsáveis pelo modelo de produção e distribuição de conteúdos comerciais na mídia eletrônica no momento em que estes apresentam imagens portadoras não de uma história cultural, mas de modelos geradores de consumo ${ }^{9}$, ampliando, via de regra, os déficits emocionais para gerar a instabilidade e o isolamento necessários para a criação de comportamentos de consumo compulsivo. O consumo é incentivado como um bem social e o fenômeno da mimese é utilizado como uma estratégia de contágio, em um processo de formação do gosto e das percepções estéticas acerca dos conteúdos recebidos. Há ainda muito a se avançar com o

9 Um exemplo claro de como isso acontece, é a tese de Carlos Henrique Aiello defendida no PPGCOM Unip em 2015.

\footnotetext{
$40 \frac{\text { Comunicação \& Inovação, PPGCOM/USCS }}{\text { v. 18, n. } 38 \text { (33-45) set-dez } 2017}$
} 
desenvolvimento do conhecimento sobre como o ser humano apreende o mundo, principalmente relacionado ao funcionamento do cérebro. Segundo Wulf (2013, p. 205), "outros estudos recentes sobre 'neurônios-espelho' têm mostrado que o reconhecimento de situações relacionadas às ações demonstra os mesmos processos que podem ser observados durante a própria ação (Rizzolatti e Craighero 2004; Iacobon 2008)". Isso significa que assistir e realizar para o cérebro é muito semelhante, no entanto só assistir promove a drástica diminuição das operações sensoriais que poderiam compor a representação cognitiva da experiência de forma complexa, realizando aquilo que Varela (1992) chamará de práticas enativas. Esses avanços nas pesquisas demonstram que o que vem sendo observado e constatado deverá ser considerado a partir de agora na exposição de crianças aos conteúdos mediáticos. A partir do conhecimento a que se tem chegado acerca dos neurônios-espelho, é preciso considerar se a mimese, que, segundo Wulf (2005), é muito mais do que mera imitação, perde no contexto da mídia eletrônica o que define a operação que garante certa autonomia individual, o componente criativo presente nas experiências miméticas, já que quem concebeu os interesses que estão por trás das imagens técnicas, conduz o processo de recepção estritamente audiovisual, retirando o componente transgressor do processo, as experiências concretas. Retirando a dimensão corporal da vivência, na televivências, o que se perde é justamente a criatividade e a autodeterminação, ou seja, a capacidade de fazer escolhas diferentes daquelas que o programa apresenta da forma já prevista.

\section{A consciência reflexiva, a liberdade de escolha e a autodeterminação}

Damásio (2000, p. 79-80) entende que houve uma negligência no estudo da importância das emoções sobre o corpo.

Durante a maior parte do século XX, a emoção não teve espaço nos laboratórios. Dizia-se que era subjetiva demais. A emoção encontrava-se no polo oposto ao da razão, sendo esta, de longe, a mais refinada das capacidades humanas, e presumia-se que a razão era totalmente independente da emoção [...] a ciência do século XX deixou o corpo de lado.

As emoções afetam o corpo, as funções motoras e somáticas e o raciocínio, e o bombardeio de imagens de violência ao qual as crianças estão submetidas no uso intenso de aparatos eletrônicos de "entretenimento" pode comprometer sua percepção e capacidade de julgamento, justamente numa fase em que se está formando a personalidade destas. Nesse caso, as operações miméticas que podem ser geradas a partir do consumo 
dessas imagens técnicas podem estimular o desejo, bem como dessensibilizar a criança, comprometendo o nível de consciência sob o qual se darão as emoções e as ações. Para que não se pense que entre emoção e ação há uma grande distância, é preciso lembrar que a palavra emoção etimologicamente significa "e/movere", "pró-movimento", ou seja, o que leva alguém a se mover.

Entender isso dentro de um contexto histórico-social tem relevância conforme explica Wulf (2005, p. 113) porque

os gestos são movimentos do corpo que mudam de significado cultural ao longo da história. [...] Os gestos se baseiam numa intenção, mas não se esgotam nela. Eles exprimem e representam emoções e se referem a objetos como também a outros indivíduos.

Para Wulf (2005), a mimese acontece na interação e contribui para a participação social, o que vai estabelecer uma forma de pertencimento e ao mesmo tempo de distinção no grupo social. Quando esse fenômeno da mimese se dá apenas pelo consumo de imagens técnicas, como televivências exclusivamente audiovisual, isso deixa de incluir o componente sensório motor, mecanismo fundamental para a apropriação da realidade de forma não passiva, criativa. Esse alheamento em relação às próprias emoções complexas, pode levar a um processo de alienação de suas necessidades reais, quando se está no uso compulsivo de aparatos tecnológicos. Os setores especializados em consumo compulsivo de aparatos eletrônicos de comunicação de clínicas psicológicas atestam isso em seu trabalho diário.

Frans de Waal (2009, p. 99) relata estudos etológicos que demonstram que "as expressões faciais exibidas numa tela não apenas fazem nossos músculos faciais se contorcer, mas também induzem nossas emoções". Waal relaciona em suas descrições o jeito como acontece a identificação com aquilo que a pessoa vê na tela. Isso se dá de forma associada com as emoções que são atingidas de forma não mediada pelo pensamento, não se tendo necessariamente consciência sobre isso, já que isso se dá por meio de processos empáticos:

Dimberg demonstrou que a empatia não depende da nossa decisão. Nós simplesmente sentimos a empatia. Depois de fixar pequenos eletrodos no rosto de seus sujeitos de forma a registrar os mínimos movimentos musculares, Dimberg apresentou a eles, numa tela de computador, fotografias de expressões faciais felizes e zangadas. Os humanos franzem o cenho em resposta a expressões faciais zangadas e erguem os cantos dos lábios em reações a expressões faciais felizes. Mas não foi essa a descoberta mais decisiva de Dimberg, pois esse tipo de imitação poderia ocorrer involuntariamente. O mais extraordinário foi que a mesma reação ocorreu quando as fotografias eram mostradas por apenas milésimos de segundos, o que impedia 
sua percepção consciente. Perguntados sobre o que tinham visto depois dessa apresentação subliminar, os sujeitos não eram capazes de dizer coisa alguma sobre as expressões felizes ou zangadas, mas as haviam reproduzido mesmo assim. As expressões faciais exibidas numa tela não apenas fazem nossos músculos faciais se contorcer, mas também induzem nossas emoções. Aqueles que tinham sido expostos a expressões felizes declaram sentir-se melhor do que aqueles que tinham sido expostos às expressões zangadas, embora nenhum grupo tivesse a menor ideia do que tinha visto (Ibid., p. 99-100).

Esses estudos são reveladores para compreender o que promove determinadas capturas tão estreitas da atenção, adesões tão vinculadas que promovem um assujeitamento a determinados conteúdos e uma limitação para a reflexão crítica. De certa forma, pode-se desencadear comportamentos que não estão na ordem da consciência, que a pessoa nem tenha como perceber, como podemos constatar, por exemplo, ao percebermos que uma criança assistindo a uma dança faz movimentos automáticos.

Segundo Wulf e Gebauer (2004, p. 14-16), “os processos miméticos desempenham um papel central para o desenvolvimento do saber prático que, dentre outros, é determinante para o agir social”. Essa observação alerta a importância da mediação dos pais e responsáveis na exposição das crianças a conteúdos em que há exploração da violência, dos conflitos latentes, do uso desigual do poder. Segundo a visão desses autores, a mediação de adultos responsáveis pode agir sobre o processo de significação na recepção dos conteúdos e das imagens, o que pode contribuir na conscientização desses conteúdos, bem como para a formação de comportamentos.

\section{Considerações finais}

Este texto abordou as consequências da hiperexposição das crianças às imagens técnicas da mídia, que além de incidirem sobre a imaginação, apresentam modelos miméticos que são subestimados em seu papel formador, tanto de personalidade como de valores, especialmente numa economia que não poupa esforços para lucrar com o consumo infantil, sem avaliar consequências. A partir de dados estatísticos que apontam o crescimento da incidência de violência urbana, propusemos a necessidade de que se considere a qualidade dos processos envolvidos contemporaneamente no ambiente imaginário e comunicativo gerado pela onipresença da mídia eletrônica. Certamente a mídia eletrônica e a apologia à violência simbólica que temos não podem ser exclusivamente responsabilizadas pelos índices de violência sociais atuais, mas também não acreditamos que elas não 
tenham nada a ver com esse quadro atual, especialmente se consideramos o efeito gerado em crianças em fase de formação de personalidade e identidade social.

A relevância dos processos miméticos e empáticos para a criação de um modelo de humanidade não pode ser minimizada, especialmente na fase da infância, momento em que a vulnerabilidade é maior, e não estar incluído nas práticas de consumo mediático do grupo pode ser sentido pela criança como uma frágil vinculação psicoafetiva e social. O descaso com o qual essas questões vêm sendo tratadas em nossa sociedade demonstram que todo o esforço para levantarmos este debate, ainda que a contrapelo das instâncias de poder, valerá a pena.

\section{Referências}

BAITELLO JUNIOR, N. A serpente, a maçã e o holograma: esboços para uma teoria da mídia. São Paulo: Paulus, 2010.

CONTRERA, M. S. Imagens endógenas e imaginação simbólica. In: CONGRESSO DA COMPÓS - ASSOCIAÇÃO NACIONAL DOS PROGRAMAS DE PÓS-GRADUAÇÃO EM COMUNICAÇÃO, 24., 2015, Brasília, DF. Anais... Brasília, DF: UnB, 2015.

DAMÁSIO, A. O mistério da consciência: do corpo e das emoções ao conhecimento de si. São Paulo: Companhia das Letras, 2000.

DURAND, G. A imaginação simbólica. Lisboa: Edições 70, 1993.

FLUSSER, V. Filosofia da caixa preta: ensaios para uma futura filosofia da fotografia. São Paulo: Hucitec, 1985.

Zona cinzenta entre ciência, técnica e arte. Cadernos de Ciência e Tecnologia, São Paulo, v. 6, n. 1, p. 149-155, jan./abr. 1989.

GEBAUER, G.; WULF, C. Mimese na cultura: agir social, rituais e jogos, produções estéticas. São Paulo: Annablume, 2004.

GIRARD, R. O bode expiatório e Deus. Covilhã: LusoSofia, 2008.

MATURANA, H. R.; VARELA, F. A árvore do conhecimento: as bases biológicas do entendimento humano. Campinas: Psy II, 1995.

MIKLOS, J. Tecnologia como religião: imaginário tecnológico e reencantamento do mundo. 2014. Trabalho apresentado ao Seminário de Estudos Avançados. São Paulo, 2014.

MORIN, E. O paradigma perdido: a natureza humana. Lisboa: Europa-América, 1988.

REIS, P. TV ainda é mais consumida que dispositivos móveis, aponta pesquisa. Revista Crescer, São Paulo, 28 nov. 2013. Disponível em: <goo.gl/pPuEEf>. Acesso em: 23 out. 2017.

SODRÉ, M. Antropológica do espelho: uma teoria da comunicação linear e em rede. Petrópolis: Vozes, 2002. VARELA, F. Sobre a competência ética. Lisboa: Edições 70, 1992.

$44 \frac{\text { Comunicação \& Inovação, PPGCOM/USCS }}{\text { v. 18, n. 38 (33-45) set-dez } 2017}$ 
WAAL, F. A era da empatia: lições da natureza para uma sociedade mais gentil. São Paulo: Schwarcz Ltda., 2009.

WULF, C. Antropologia da educação. Campinas: Alínea, 2005.

. Homo pictor: imaginação, ritual e aprendizado mimético no mundo globalizado. São Paulo: Hedra, 2013. 